\title{
Análise multiescala a partir de wavelets não decimadas: investigação dos efeitos da cintilação ionosférica nos sinais GPS
}

\author{
Gabriela de O. N. Brassarote ${ }^{1}$ \\ Pós-Graduação em Matemática Aplicada e Computacional, FCT/UNESP \\ 19060-900, Presidente Prudente, SP \\ E-mail: gabrielabrassarote@gmail.com \\ Eniuce M. de Souza \\ Departamento de Estatística, Universidade Estadual de Maringá - UEM \\ 87020-900, Maringá, PR \\ E-mail: emsouza@uem.br \\ João F. G. Monico \\ Departamento de Cartografia, FCT/UNESP \\ 19060-900, Presidente Prudente, SP \\ E-mail: galera@fct.unesp.br \\ Aylton Pagamisse \\ Departamento de Matemática, Estatística e Computação, FCT/UNESP \\ 19060-900, Presidente Prudente, SP \\ E-mail: aylton@fct.unesp.br
}

\begin{abstract}
RESUMO
A crescente influência do GPS (Global Positioning System) na navegação e no sensoriamento remoto é bastante evidente nos dias atuais. No entanto, até que o sinal do satélite chegue ao receptor GPS, efeitos, muitas vezes severos, acabam por exercer influência sobre o sinal, ocasionando erros ou até mesmo a perda do sinal do satélite pelo receptor.

A cintilação ionosférica é um dos meios mais severos que causa interferência sobre sinais de rádio, inclusive os sinais GPS. Ela é causada por irregularidades na densidade dos íons presentes na ionosfera que, ao formarem bolsas de concentração local, produzem descontinuidades na ionosfera. Um sinal que por ali atravesse, sofre refração chegando até seu receptor via dois caminhos, o caminho direto e o refratado. O sinal resultante é o vetor adição dos sinais direto e refratado [1] e pode, no caso do sistema GPS, conter erros significativos nas medidas de posicionamento.

Por possuir natureza aleatória e aparentemente não correlacionada, a modelagem da cintilação tem sido inviável. No entanto, através de informações quantitativas do índice de cintilação, como o índice S4 que quantifica a cintilação em potência (amplitude), é possível caracterizar e entender as irregularidades ionosféricas que causam a cintilação.

O objetivo deste trabalho é investigar os efeitos da cintilação ionosférica nos sinais de satélite GPS através da análise da série temporal proveniente dos índices S4 de cintilação. Tais séries podem ser não estacionárias, exigindo um método adequado para tal análise. Uma análise tradicional de wavelets, por si só já permite uma análise não paramétrica para séries temporais não estacionárias. Em sua versão decimada, a Transformada Wavelet Discreta (TWD) já tem contribuído bastante para o avanço do posicionamento por satélite [5], entretanto, devido à usual decimação por 2 , em cada escala tem-se metade dos coeficientes da escala anterior. Para uma análise completa em multiescala seria necessário que o mesmo número de coeficientes correspondendo a todos os instantes de tempo em que os dados foram coletados fosse mantido para cada escala. Isso é possível com a Transformada Wavelet Discreta Não Decimada (TWND), a qual é invariante por translação [4], [3]. Dessa forma, informações e padrões
\end{abstract}

\footnotetext{
${ }^{1}$ Bolsista Fapesp.
} 
escondidos, que não podem ser detectados no domínio do tempo, podem ser explicitados no domínio espaço/freqüência.

No procedimento de investigação do efeito da cintilação ionosférica, as séries temporais obtidas dos índices S4 foram analisadas em multiescala/multirresolução pela TWND, sendo necessário identificar uma wavelet mãe ideal. Inicialmente adotou-se a família de wavelets Symmlets com 10 momentos nulos (SYM10). Posteriormente, a wavelet Starlet foi aplicada e os resultados, comparados. A wavelet Starlet, chamada no passado como B3-spline, é muito utilizada na análise de dados astronômicos, em que os objetos de estudo são na maioria das vezes isotrópicos [6]. Além da fácil implementação, outra razão que motiva o uso da Starlet é que ela não necessita de filtros ortogonais ou biortogonais e ainda oferece uma computação rápida, ideal para lidar com dados de grande escala, como é o caso dos dados S4 de cintilação, coletados em intervalos de até $100 \mathrm{~Hz}$. A implementação foi realizada em linguagem $\mathrm{R}$ (http://cran.r-project.org/), em que rotinas de código aberto, tais como os pacotes wavethresh, tseries, dentre outros, foram utilizadas [2].

Resultados preliminares mostram a presença de um padrão que se repete na série em dias consecutivos em que há presença de dados. Tal comportamento periódico, que apresenta formato de "U", mostrou-se inversamente relacionado com o ângulo de elevação e diretamente relacionado com o efeito do multicaminho, o qual ocorre devido à reflexão dos sinais do satélite em superfícies nas proximidades do receptor. Como este efeito pode influenciar na análise do índice S4 de cintilação ionosférica, embora seja difícil, faz-se necessário eliminá-lo. A partir da decomposição em multiescala do período com baixo índice de cintilação foi proposto nesse trabalho estimar o efeito do multicaminho, ou seja, identificar as escalas em que este efeito ocorre e separá-lo do efeito da cintilação. A validação desse procedimento pode ser realizada pela verificação do fato de que o efeito do multicaminho se repete diariamente se o ambiente permanece inalterado. Uma vez estimado, esse efeito pode ser removido inclusive em períodos de forte cintilação ionosférica.

Portanto, esse trabalho apresenta uma metodologia inovadora para a investigação dos efeitos da cintilação ionosférica sobre os sinais GPS através da análise do espectro wavelet da série temporal dos índices S4 de cintilação, além de dar um primeiro passo em direção a separar o efeito da cintilação de outros efeitos que podem influenciar a análise dos índices S4. Quando comparados os resultados obtidos com a aplicação de diferentes bases wavelet na análise em questão, pode-se afirmar que ambos foram satisfatórios e análogos. No entanto, a wavelet Starlet se destaca por apresentar maior rapidez computacional no cálculo da TWND e lidar melhor com os problemas de borda.

Palavras-chave: Wavelets Não Decimadas, Análise Multiescala, Séries Temporais, Cintilação Ionosférica, GPS.

\section{Referências}

[1] A. K. Maini, V. AGRAWAL, Satellite Technology: Principles and Applications.Wiley, India, 2007.

[2] G. P. Nason, Wavelet Methods in Statistics with R. Springer, New York, 2008.

[3] G. P. Nason, B. W. Silverman, The stationary wavelet transform and some statistical applications. In Lecture Notes in Statistics, n. 103, Springer-Verlag, 1995, 281-299.

[4] D.B. Percival, A.T. Walden, Wavelets Methods for Time Series Analysis, Cambridge University Press, Cambridge, England, 2000.

[5] E. M. Souza, Análise de Wavelets para Detecção e Correção do Multicaminho no Posicionamento Relativo GNSS estático e Cinemático. PhD thesis, Faculdade de Ciências e Tecnologia, Universidade Estadual do Estado de São Paulo, Presidente Prudente, 2008.

[6] J.L. Starck, F. Murtagh, J. Fadili, Sparse image and signal processing. Wavelets, curvelets, morphological diversity (CUP, 2010)(ISBN 0521119138)(O)(351s)_CsIp_. 